\title{
MODEL HUBUNGAN TINGGI DAN DIAMETER POHON AKASIA (Acacia auriculiformis) SEBAGAI PENGHASIL KAYU ENERGI DI KABUPATEN PURWOKERTO PROVINSI JAWA TENGAH
}

\author{
(The Relationship Model of Height and Diameter of Acacia Trees (Acacia auriculiformis) \\ as a Wood Energy Source in Purwokerto Central Java) \\ Sofwan Bustomi dan Mira Yulianti \\ Pusat Litbang Peningkatan Produktivitas Hutan \\ Kampus Balitbang Kehutanan, Jl. Gunung Batu No. 5 Po.Box 331, Bogor 16610, Indonesia \\ Tel. 0251-8631238, Fax. 0251-7520005
}

Naskah masuk : 15 Februari 2013; Naskah diterima : 29 Agustus 2013

\begin{abstract}
The objective of this study was to determine the best height and diameter relationship model of Acacia auriculiformis, as wood energy. The study was conducted at six locations in Banyumas District. Data collection was systematically conducted at equal interval in each location. Of the 215 trees model measured, only 36 trees that can be used in the regression equation for height-diameter and distribution of trees relationship with diameter of trees ranging from 2.9 to $27.2 \mathrm{~cm}$ with a height ranging from 5.5 to $26.5 \mathrm{~m}$. The results of the analysis of the three linear models which were tested, based on the criteria of coefficient of determination ( $r 2)$, a model that uses dependent maximum height variable has $r 2$ value which is greater than the model that uses dependent total maximum height variable, so the estimator model used is model that uses dependent total maximum height variable. Based on the scoring approach, the selected equation, with average amount of bias, central squares estimator error (MSEP) and error index (EI), are $0.02873,38.51$, and 80.9073 respectively.
\end{abstract}

Keywords: Height, diameter, acacia, equation

\begin{abstract}
ABSTRAK
Tujuan Penelitian ini untuk mengetahui model terbaik dari hubungan tinggi dan diameter pada tanaman penghasil kayu energi. Penelitian ini dilakukan pada enam lokasi Kabupaten Banyumas. Pengambilan dipilih secara sistematis dengan jarak sama pada masing-masing lokasi. Dengan 215 pohon model yang diukur, dan 36 pohon validasi yang dapat digunakan dalam penyusunan persamaan regresi hubungan diameter-tinggi pohon dengan sebaran diameter antara 2,9-27,2 cm dengan tinggi antara 5,5-26,5 $\mathrm{m}$. Hasil analisis terhadap 3 model linear yang dicoba, bahwa berdasarkan kriteria besarnya koefisien determinasi $\left(\mathrm{r}^{2}\right)$, model yang menggunakan peubah tak bebas tinggi maksimum mempunyai nilai $\mathrm{r}^{2}$ yang lebih besar dibandingkan dengan model yang menggunakan peubah tak bebas tinggi seluruh pohon sehingga penduga model yang digunakan adalah model yang menggunakan peubah tak bebas tinggi total maksimum. Berdasarkan pemeringkatan dengan pendekatan scoring, persamaan terpilih yaitu $\mathrm{H}=1.3+$ $0,606 \mathrm{D}^{0,748}$, Dengan besarnya bias rata-rata, penduga kuadrat tengah galat (MSEP) dan indeks galat (EI), berturutturut sebesar 0,02873; 38,51; dan 80,9073.
\end{abstract}

Kata kunci : Tinggi, diameter, akasia, persamaan

\section{PENDAHULUAN}

Pemanenan yang melebihi kapasitas pertumbuhan tegakan setempat akan menyebabkan tidak tercapainya azas kelestarian; dan sebaliknya apabila intensitas pemanenan terlampau rendah berarti pemanfaatan sumberdaya hutan tidak optimal dan mengurangi pendapatan usaha, yang secara langsung menurunkan rentabilitasi usaha hutan tanaman (Siswanto, 2008).

Menurut Hadi dan Nuhamara (1996), Pemerintah Indonesia telah memulai program penana- man tanaman akasia dalam perkebunan skala besar sejak tahun 1984. Kayu merupakan sumber energi biomassa utama bagi jutaan orang di negara berkembang. Permintaan akan kayu meningkat setiap tahunnya seiring meningkatnya jumlah penduduk (World Wide Wattle, 2004).

Tanaman akasia (Acacia sp.) telah ditanam di lebih dari 80 negara di dunia termasuk Indonesia. Tanaman akasia ini dapat digunakan untuk berbagai keperluan seperti diambil kayunya, diolah bubur kayu (wood pulp), kertas, bahan bakar (fuel) dan sebagainya (Eldoma dan awing, 1999). 
Beberapa spesies tanaman akasia yang dikembangkan di Indonesia adalah $A$. auriculiformis, $A$. mangium, A. Crassicarpa, dan A. aulacocarpa (Zulfiyah dan Gales, 1996).

Pada umumnya, informasi pertumbuhan dan hasil dalam ukuran kuantitatif dirangkum dalam bentuk model pertumbuhan atau model hasil yang merupakan hubungan parameter tegakan dengan umur. Berdasarkan model ini, dapat diproyeksikan kondisi tegakan pada setiap umur sehingga memungkinkan pihak pengelola memperoleh informasi yang diperlukan dalam pengambilan keputusan manajemen, diantaranya yang berhubungan dengan penentuan rotasi tebang (daur) berazaskan kelestarian. Sehubungan dengan hal tersebut model pertumbuhan atau model hasil harus disusun di setiap unit pengelolaan hutan tanaman. Sutarahardja (1992) menyebutkan bahwa pertumbuhan merupakan proses fisiologi yang berlangsung terus menerus hingga pohon atau tegakan mati secara alami, sedangkan Prodan (1968) mendefinisikan pertumbuhan sebagai suatu sistem organik di dalam waktu tertentu yang diukur menurut satuan panjang, berat, isi dan luas.

Dalam lingkup Perum Perhutani, pengelolaan hutan tanaman masih didasarkan pada Tabel Tegakan Sepuluh Jenis (Suharlan et al., 1975). Tabel tegakan tersebut disusun berdasarkan data yang dikumpulkan pada tahun sebelum 1970 . Mengingat kemungkinan keadaan (pertumbuhan) tegakan hutan saat berbeda dibanding keadaan sebelumnya baik disebabkan oleh perubahan tingkat pengelolaan maupun perbedaan keadaan lingkungannya, maka perbaikan (revisi) atas tabel tersebut menjadi sangat penting. Ketidakcocokan kondisi tegakan di lapangan dengan tabel tegakan sudah sering dirasakan oleh para pelaksana lapangan dalam pengelolaan hutan.

Setiap pohon mengalami dua bentuk pertumbuhan yang berbeda, yaitu pertumbuhan vertikal atau tinggi dan pertumbuhan horizontal atau diameter. Oleh karena kedua pertumbuhan tersebut sangat menentukan besaran volume pohon, maka untuk simplikasi model penduga volume dengan memilih salah satu karakteristik sebagai peubah penduga (predictor variable) selalu didahului pengujian keeratan atau model hubungan antara karakteristik tersebut. Meskipun demikian, pertumbuhan suatu pohon dipengaruhi oleh kemampuan genetiknya dalam berinteraksi dengan faktor lingkungan seperti iklim, tanah dan topografi serta kemampuan berkompetisi dalam memperoleh makanan dan ruang tumbuh. Jadi setiap jenis atau kelompok jenis pohon dapat mempunyai pertumbuhan dan ukuran batang yang berbeda sebagai akibat dari interaksi faktor-faktor tersebut (Husch et al., 1972; Huang et al., 2000). Adapun tujuan penelitian ini untuk melihat model pendugaan terbaik antara tinggi dan diameter pada tanaman penghasil kayu energi jenis akasia.

\section{METODE PENELITIAN}

\section{A. Bahan dan Alat penelitian}

Bahan yang digunakan adalah pohon model A. auriculiformis yang terdapat pada 2 lokasi hutan rakyat di kabupaten yang terletak di Desa Jingkang, Kecamatan Ajibarang dan di Desa Sawangan, Kecamatan Ajibarang Kabupaten Purwokerto Provinsi Jawa Tengah. Alat-alat yang digunakan adalah roll meter, pita diameter, Hagameter, GPS, Abney Level, komputer, seperangkat alat keamanan kerja dan survei, serta alat tulis.

\section{B. Metode}

Metode penelitian, meliputi pengumpulan data, ekplorasi/filtering data, penyusunan model persamaan regresi, dan validasi model. Pengumpulan data pohon model dilakukan cara pengukuran diameter dan tinggi pohon terhadap seluruh pohon yang terdapat pada 6 petak ukur permanen (PUP) berukuran masing-masing $40 \times 40 \mathrm{~m}(0,16$ ha); eksplorasi/filtering data berdasarkan diagram tebar menurut diameter dan tinggi pohon; pemilahan data terpilih (partitioning data) yang terdiri 215 pohon model utuk penyusunan dan 36 pohon model untuk validasi model (inde-pendent or external validation). Penyusunan beberapa persamaan regresi hubungan diametertinggi pohon berdasar model, yaitu :

$$
\begin{aligned}
& \text { 1. MT1: } \mathrm{H}=1,3+a e^{\frac{b}{D}} \quad \text { (Loetsch, 1973) } \\
& \text { 2. MT2: } H=1.3+a D^{b} \quad \text { (Stoffel and van Soest, 1975; Stage, 1975) } \\
& \text { 3. МT3: } \mathrm{H}=1,3+\frac{D^{\llcorner}}{a+b D^{2}} \text { (Meyer, 1940; F Farr et al, 1989, Noffat et al , } 1991
\end{aligned}
$$

dimana: $\mathrm{H}$ adalah tinggi total pohon (m); $\mathrm{D}$ adalah diameter setinggi dada $(\mathrm{cm})$; a dan $\mathrm{b}$ adalah penduga parameter 
Untuk menentukan model mana yang paling baik sebagai penduga hubungan antara diameter dan tinggi pohon, dilakukan validasi terhadap ketiga model tersebut. Salah satu pendekatan yang dilakukan sebagai pertimbangan untuk melakukan validasi menurut Draper dan Smith (1992) adalah membuang "m" amatan dan menggunakan "n-m" amatan lainnya untuk memperoleh persamaan regresi. Selanjutnya memvalidasi persamaan tersebut dengan $\mathrm{m}$ amatan yang dibuang. Kriteria yang digunakan dalam melakukan validasi adalah besarnya bias rata-rata absolut, mean squared error prediction (MSEP) dan Indeks galat (EI). Semakin rendah nilai ketiganya semakin baik penduga model yang digunakan. Penduga model dengan nilai bias, MSEP dan EI terendah diberi skor 3 , sedang penduga model dengan nilai tertinggi diberi skor 1. Penduga model dengan jumlah total skor tertinggi dipertimbangkan sebagai model terbaik. Rumus bias rata-rata dan MSEP (Rawlings, 1988) serta EI (Reynolds et al. 1988) adalah:

$$
\begin{gathered}
\text { Bias }=\frac{\sum_{i=1}^{n}(Y i-\hat{Y} i)}{n} \ldots . . . \\
M S E P=\frac{\sum_{i=1}^{n}(Y i-\hat{Y} i)^{2}}{n} \\
E i=\sum_{i=1}^{n}|Y i-\hat{Y} i|
\end{gathered}
$$

Di mana: $Y_{\mathrm{i}}$ adalah nilai pengamatan ke $\mathrm{i} ; \hat{Y}$ adalah nilai dugaan ke I; $\mathrm{N}$ adalah banyaknya pengamatan

\section{HASIL DAN PEMBAHASAN}

\section{A. Sebaran Diameter}

Pohon model yang digunakan sebanyak 215 pohon untuk dijadikan model dan penyusunan persamaan regresi. Diameter pohon hasil pengukuran berkisar antara 2,9-27,2 cm dengan ratarata $12,8 \mathrm{~cm}$. Tinggi pohon berkisar antara 5,5$26,5 \mathrm{~m}$ dengan rata-rata $13,7 \mathrm{~m}$. Sebaran diameter pohon model yang terukur berdasarkan tingginya tercantum pada Tabel 1, dan diagram pencar dapat dilihat pada Gambar 1.

\section{B. Hubungan antara Diameter dan Tinggi Pohon}

Gambar 1. menunjukkan bahwa secara umum pohon yang mempunyai diameter antara 4-24 cm mempunyai tinggi total rata-rata masih di bawah $20 \mathrm{~m}$, kemudian ada kecenderungan tinggi pohon mengalami kenaikan yang relatif kecil pada kisaran diameter antara 24-29 cm. Fakta ini merupakan suatu indikasi bahwa pertumbuhan tinggi pohon pada kisaran diameter tersebut sudah mencapai pertumbuhan maksimum.

Dan menghasilkan persamaan regresi sebagai berikut :

$$
\begin{aligned}
& M T 1: H=1,3+2,97^{\frac{-5,31}{D}} \\
& M T 2: H=1.3+0,606 D^{0,748} \quad \ldots \ldots . . \\
& M T 3: H=1,3+\frac{D^{2}}{0,0734+1,57 D^{2}}
\end{aligned}
$$

Tabel (Table) 1. Sebaran pohon model Acacia auriculiformis berdasarkan kelas diameter dan tinggi pohon (Distribution of models Acacia auriculiformis trees by diameter and tree height classes)

\begin{tabular}{lcccccc}
\hline Kelas & \multicolumn{5}{c}{ Tinggi pohon $(\mathrm{m})$} & \multirow{2}{*}{ Jumlah } \\
\cline { 2 - 5 } diameter $(\mathrm{cm})$ & $4-9$ & $9-14$ & $14-19$ & $19-24$ & $24-29$ & 17 \\
\hline $2-5$ & 17 & 14 & & & & 34 \\
$5-9$ & 20 & 30 & 5 & & & 38 \\
$9-12$ & 3 & 38 & 25 & 5 & & 68 \\
$12-16$ & & 23 & 10 & 3 & 45 \\
$16-20$ & & 4 & 3 & 2 & 9 \\
$20-24$ & & & 3 & 1 & 4 \\
$24-28$ & 40 & 91 & 57 & 21 & 6 & 215 \\
\hline
\end{tabular}




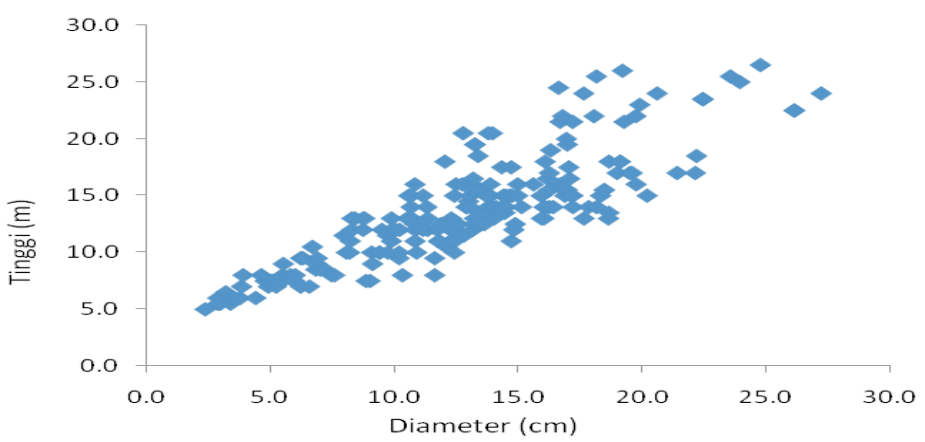

Gambar (Figure) 1. Diagram pencar hubungan tinggi dan diameter model (Scatter diagram of height and diameter relationship models)

Tabel(Table) 2. Penduga parameter dan koefisien determinasi hubungan diameter dan tinggi pohon Acacia auriculiformis (Parameter estimators and the coefficient of determination of tree height and diameter relationship weru)

\begin{tabular}{cllll}
\hline \multirow{2}{*}{ No } & Model & \multicolumn{2}{c}{ Penduga Parameter } & \multirow{2}{*}{$\mathrm{R}^{2}$} \\
\cline { 3 - 4 } & & $\mathrm{a}$ & $\mathrm{b}$ & 69,8 \\
1. & MT1 & 2,97 & $-5,31$ & 80,1 \\
3. & MT2 & 0,606 & 0,748 & 70,8 \\
\hline
\end{tabular}

Tabel(Table) 3. Sebaran pohon model validasi Acacia auriculiformis berdasarkan kelas diameter dan tinggi pohon (Distribution model validation of Acacia auriculiformis trees by diameter class and tree height)

\begin{tabular}{cccccc}
\hline \multirow{2}{*}{ Kelas diameter $(\mathrm{cm})$} & \multicolumn{2}{l}{ Tinggi pohon $(\mathrm{m})$} & Jumlah \\
\cline { 2 - 6 } & $4-10$ & $10-16$ & $16-21$ & $21-27$ & 10 \\
\hline $2-5$ & 10 & & & & 15 \\
$5-9$ & 11 & 4 & & & 7 \\
$9-12$ & 2 & 5 & & & 15 \\
$12-16$ & & 14 & 1 & 1 & 4 \\
$16-20$ & 3 & 1 & 1 & 1 \\
$20-24$ & & & & 2 & 53 \\
$24-28$ & 23 & 26 & 2 & & 1 \\
\hline Jumlah & & & & & \\
\hline
\end{tabular}

Hasil analisis regresi menunjukkan bahwa ada hubungan yang nyata antara tinggi dengan diameter pohon, baik yang menggunakan peubah tak bebas tinggi setiap individu pohon maupun tinggi maksimum. Hal ini sesuai dengan yang dinyatakan oleh Husch et al. (1972) bahwa jika ada dua variabel mempunyai korelasi dengan variabel lain maka kedua variabel tersebut akan berkorelasi satu dengan lainnya. Karena pertumbuhan tinggi dan diameter merupakan fungsi dari waktu yang berarti bahwa tinggi dan diameter mempunyai korelasi dengan waktu maka tinggi dan diameter mempunyai korelasi yang cukup kuat.
Kuatnya hubungan antara tinggi dan diameter dinyatakan dengan besarnya nilai $\mathrm{R} 2$ dan model penduga parameter dari ke tiga model yang dianalisis seperti yang disajikan pada Tabel 2 .

Untuk mengetahui model terbaik dari ketiga persamaan regresi yang telah dihasilkan, dilakukan validasi terhadap ketiga persamaan tersebut. Validasi model dilakukan dengan menggunakan data yang berbeda sebanyak 36 pohon model. Sebaran diameter pohon validasi berdasarkan tingginya tercantum pada Tabel 3, dan diagram pencar dapat dilihat pada Gambar 2. 


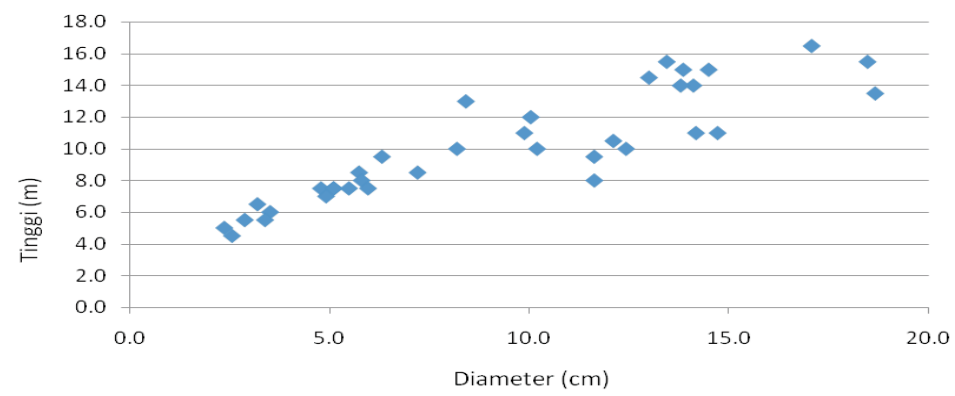

Gambar(Figure) 2. Diagram pencar hubungan tinggi dan diameter untuk model validasi (Scatter diagram of height and diameter relationship for validation model)

Tabel (Table) 4. Validasi penduga model hubungan tinggi dan diameter (Validation of estimator model of height and diameter relationship)

\begin{tabular}{|c|c|c|c|c|c|c|c|c|c|}
\hline \multirow{2}{*}{ No } & \multirow{2}{*}{ Model } & \multirow{2}{*}{$\begin{array}{l}\text { Bias } \\
\text { Nilai }\end{array}$} & \multirow[b]{2}{*}{ Skor } & \multicolumn{2}{|l|}{ MSEP } & \multicolumn{2}{|c|}{ Indeks Galat (EI) } & \multirow{2}{*}{$\begin{array}{l}\text { Total } \\
\text { Skor }\end{array}$} & \multirow{2}{*}{ Peringkat } \\
\hline & & & & Nilai & Skor & Nilai & Skor & & \\
\hline 1. & MT1 & $-0,0331$ & 1 & 53,067 & 2 & $-43,708$ & 3 & 6 & 2 \\
\hline 2. & MT2 & $-0,0335$ & 2 & 52,391 & 3 & 80,9073 & 2 & 7 & 1 \\
\hline 3. & MT3 & $-0,101$ & 3 & 482,878 & 1 & $-80,907$ & 1 & 5 & 3 \\
\hline
\end{tabular}

Hasil validasi terhadap ketiga persamaan regresi yang dihasilkan dinyatakan berdasarkan besarnya nilai Bias, MSEP dan EI yang disajikan pada Tabel 4.

Berdasarkan peringkat yang diperoleh sesuai dengan total skor hasil validasi, Posisi tiga model dengan peringkat terbaik berturut-turut adalah MT2, MT1 dan Mt3.

\section{KESIMPULAN}

Dari hasil analisis dapat terlihat bahwa persamaan linear yang terbaik dari ketiga model untuk menduga Hubungan Tinggi dan Diameter Pohon akasia di kabupaten purwokerto adalah persamaan ke 2 yaitu $\mathrm{H}=1.3+0,606 \mathrm{D}^{0,748}$ untuk selang diameter $2-28 \mathrm{~cm}$.

\section{DAFTAR PUSTAKA}

Draper, N.R. dan Smith, H. 1992. Analisis Regresi Terapan (Alihbahasa oleh Bambang Sumantri). Edisi Kedua. PT Gramedia Pustaka Utama. Jakarta.

Eldoma A., Awang K. 1999. Site Adaptability of Acacia mangium, Acacia auriculiformis, Acacia aulacocarpa. CIFOR Publication.
Farr, W.A., D.J. DeMars, and J.E. Dealy.1989. Height and Crown Width Related to Diameter for Open-Grown Western Hemlock and Sitka Spruce. Can. J. For. Res. 19: 1203-1207.

Hadi, S, Numahara S.T. 1996. Diseases of Spesies and Provenances of Acacias in West and South Kalimantan, Indonesia. Dalam: Old KM et al., editor. Proceding of an International Workshop held Subanjeriji (South Sumatera), 28 April - 3 Mei 1996. CIFOR Special Publication. 23-47.

Huang, S., Price, D., and Titus, S.J. 2000. Development of Ecoregion-Based Height-Diameter Models for White Spruce in Boreal Forests. Forest Ecology and Management 129, 125141.

Husch, B., Miller, C.I. and Beers, T.W. 1972. Forest Mensuration. Second Edition. The Ronald Press Company. New York.

Loetsch, F., F. Zöhrer, and K.E. Haller. 1973.Forestry Inventory, Vol. 2. BLV Verlagsgesellschaft $\mathrm{mbH}$, Munich, Germany.

Meyer, H.A. 1940. A Mathematical Expression for Height Curves. J. For. 38: 415-420.

Moffat. A.J., R.W. Mattews, and J.E. Hall. 1991.The Effects of Sewage Sludge on Growth and Foliar and Soil Chemistry in Pole-Stage Corsican Pine at Ringwood Forest, Dorset, UK. Can. J. For. Res. 21: 902-909.

Prodan, M. 1968. Forest Biometric. Perganon. Oxford-London. 
Rawlings, J.O. 1988. Applied Regression Analysis : A Research Tool. Wadsworth \& Brooks/Cole Advanced Books \& Software. Pacific Grove, California.

Reynolds, M.R., Burk, T.E., and Huang, W.C. 1988. Goodness of fit tests and Model Selection Procedures for Diameter Distribution Model. Forest Science 34: 373-399.

Siswanto. Bambang. 2008. Model Hasil Diameter dan Tinggi Hutan Tanaman Damar (Agathis loratifolia Salisb.) di Daerah lumajang, Jawa Timur. Mitra Hutan Tanaman Vol.3 No.2, Juli 2008.93 - 97.

Suharlan, A., K. Sumarna, J. Sudiono. 1975. Tabel Tegakan Sepuluh Jenis Kayu Industri (Yield Table of Ten Industrial Wood Species). Bogor: Badan Penelitian dan Pengembangan Kehutanan. Bogor.
Sutarahardja, S. 1982. Inventarisasi Hutan. Departemen Manajemen Hutan-Fakultas Kehutanan Institut Pertanian Bogor.

Stage, A.R. 1975. Prediction of Height Increment for Models of Forest Growth.USDA For. Serv., Res. Pap. INT-164.

Stoffels, A. and J. van Soest. 1953. The Main Problems in Sample Plots. 3. Height Regression. Ned Bosbouwtijdschr. 25: 190-199. [English summary in For. Abstr. 15:77].

World Wide Wattle. 2004. Wood Products. http:// www.ffp.csiro.au//. Diakses tanggal 6 Februari 2013.

Zulfiyah, A. Gales, K. 1996. Diseases of Tropical Acacias in South Sumatera. Dalam: Old KM et al., editor. Proceding of an International Workshop held Subanjeriji (South Sumatera), 28 April - 3 Mei 1996. CIFOR Special Publication. 48-52. 